\title{
A Simple Method to Avoid Bile Duct Injury during Percutaneous Radiofrequency Ablation Therapy for Hepatocellular Carcinoma
}

\author{
Hidetaka Takashima $^{a} \quad$ Michihisa Moriguchi $^{b}$ Natsuko Hayashic \\ Kyohei Ikeda ${ }^{a}$ Kiyoshi Ogiso ${ }^{a}$ Chihiro Yokomizo $^{a}$ Hirokazu Uejima $^{a}$ \\ Tadashi Itoh $^{a}$ Hideo Tomioka $^{a}$ Shigeto Mizuno ${ }^{a}$ d Seiji Shimizu ${ }^{a}$ \\ Koichiroh Yasui $^{\mathrm{b}}$ Yoshito Itoh $^{\mathrm{b}}$

\begin{abstract}
aDepartments of Gastroenterology and Hepatology, Osaka General Hospital of WEST Japan Railway Company, Osaka, Japan; 'bepartment of Molecular Gastroenterology and Hepatology, Kyoto Prefectural University of Medicine Graduate School of Medical Science, Kyoto, Japan; 'Department of Radiology, Osaka General Hospital of WEST Japan Railway Company, Osaka, Japan; dDepartment of Endoscopy, Kinki University Nara Hospital, Nara, Japan
\end{abstract}

\section{Keywords}

Percutaneous radiofrequency ablation $\cdot$ Hepatocellular carcinoma $\cdot$ Percutaneous transhepatic cholangiodrainage $\cdot$ Intraductal chilled saline perfusion

\begin{abstract}
Hepatocellular carcinoma represents a major global health burden. Its treatment is often complicated by the anatomical location of tumors, which can lead to adverse outcomes. Radiofrequency ablation has recently gained attention as a safe method for treating hepatocellular carcinoma, but only in tumors that are not adjacent to bile ducts. Here, we report a new method for cooling the bile duct during radiofrequency ablation therapy, in which the outer jacket of an elastor needle was fixed and flash-cooled with chilled saline. This method was applied in a patient with hepatocellular carcinoma tumors near the main bile duct. The patient underwent successful radiofrequency ablation with bile duct cooling. The advantages of this method include low medical cost, simpler securing of nonexpanded bile ducts, and simultaneous removal upon termination of the radiofrequency ablation therapy. Bile duct complications associated with radiofrequency ablation typically have delayed onset. Computed tomography examination 2 months after treatment showed no bile duct injury in this case.
\end{abstract}




\section{Case Reports in Oncology}

Case Rep Oncol 2020;13:1337-1342

\begin{tabular}{l|l}
\hline DOI: $10.1159 / 000510043$ & (c) 2020 The Author(s). Published by S. Karger AG, Basel
\end{tabular} www.karger.com/cro

Takashima et al.: Avoiding Bile Duct Injury during RFA for HCC

\section{Introduction}

Hepatocellular carcinoma (HCC) is the second-leading cause of cancer-related death [1]. The major risk factors for HCC in contemporary clinical practice include post-sustained virological response hepatitis $\mathrm{C}$, treatment-suppressed hepatitis B virus, alcoholic and nonalcoholic fatty liver disease, and dietary exposure to aflatoxins B1 in developing countries. Radiofrequency ablation (RFA) is frequently used for the local treatment of HCC [2-6]. RFA is the best treatment alternative in patients with early-stage HCC who are not eligible for surgical resection. RFA was shown to extend survival by $>60$ months in patients with HCC [6]. HCC is often anatomically complex, leading to difficulty with treatment. Glisson's capsule extends into the liver as sheaths around the hepatic bile ducts, hepatic arteries, and portal veins. HCC lesions adjacent to Glisson's capsule may be affected by RFA, thus increasing the risk of complications, such as intrahepatic bile duct dilatation, hepatic arterioportal fistula, and hepatic infarction. Most of these complications are irreversible and may negatively affect liver function and prognosis. Wakamatsu et al. [6] reported that arterioportal fistula, intrahepatic bile duct dilatation, and hepatic infarction caused by RFA developed in 10.0, 8.2, and $1.2 \%$ of patients, respectively.

Because bile duct damage is very serious in the hilar region, central liver tumors are considered to be a contraindication for RFA [7-9]. Various mitigating measures have been reported, such as cooling the tissue by infusing chilled saline through the endoscopic nasobiliary drainage (ENBD) tube or percutaneous transhepatic cholangiodrainage (PTCD) tube $[7,10-12]$. Acute pancreatitis occasionally occurs, which may be a critical complication [10, 11]. Here, we report a safer and more effective new method of cooling the bile duct during RFA therapy for HCC.

\section{Case Report}

In April 2020, an 86-year-old man visited the Department of Gastroenterology due to an intrahepatic lesion. He was a long-time drinker but had normal liver function (Table 1). His liver function was sufficient for RFA therapy, with a Child-Pugh classification of A and ALBI grade 2 , but the tumor was located near the main bile duct. We obtained informed consent

Table 1. Patient laboratory data on admission

\begin{tabular}{llll}
\hline WBC & $8,200 / \mu \mathrm{L}$ & eGFR & $60.8 \mathrm{~mL} / \mathrm{min} / 1.73 \mathrm{~m}^{2}$ \\
$\mathrm{RBC}$ & $30.8 \times 10^{6} / \mu \mathrm{L}$ & $\mathrm{Na}$ & $131 \mathrm{mEq} / \mathrm{L}$ \\
$\mathrm{Hb}$ & $10.8 \mathrm{~g} / \mathrm{dL}$ & $\mathrm{K}$ & $5.0 \mathrm{mEq} / \mathrm{L}$ \\
$\mathrm{Ht}$ & $31.7 \%$ & $\mathrm{Cl}$ & $96 \mathrm{mEq} / \mathrm{L}$ \\
$\mathrm{PLT}$ & $18.6 \times 10^{4} / \mu \mathrm{L}$ & $\mathrm{T}-\mathrm{cho}$ & $151 \mathrm{mg} / \mathrm{dL}$ \\
$\mathrm{PT}$ & $76 \%$ & $\mathrm{TG}$ & $57 \mathrm{mg} / \mathrm{dL}$ \\
$\mathrm{TP}$ & $6.2 \mathrm{~g} / \mathrm{dL}$ & HDL-C & $76 \mathrm{mg} / \mathrm{dL}$ \\
$\mathrm{ALB}$ & $3.7 \mathrm{~g} / \mathrm{dL}$ & LDL-C & $53 \mathrm{mg} / \mathrm{dL}$ \\
AST & $20 \mathrm{IU} / \mathrm{L}$ & GLU & $72 \mathrm{mg} / \mathrm{dL}$ \\
ALT & $10 \mathrm{IU} / \mathrm{L}$ & S-AMY & $74 \mathrm{IU} / \mathrm{L}$ \\
$\mathrm{LDH}$ & $236 \mathrm{IU} / \mathrm{L}$ & HbA1c & $5.3 \%$ \\
ALP & $308 \mathrm{IU} / \mathrm{L}$ & CRP & $0.67 \mathrm{mg} / \mathrm{dL}$ \\
$\gamma \mathrm{GTP}$ & $37 \mathrm{IU} / \mathrm{L}$ & AFP & $3.9 \mathrm{ng} / \mathrm{mL}$ \\
T-Bil & $0.7 \mathrm{mg} / \mathrm{dL}$ & PIVKAII & $52 \mathrm{mAU} / \mathrm{mL}$ \\
ChE & $158 \mathrm{IU} / \mathrm{L}$ & HBs$-A g$ & $(-)$ \\
BUN & $24 \mathrm{mg} / \mathrm{dL}$ & HBs-Ab & $(-)$ \\
Cre & $0.90 \mathrm{mg} / \mathrm{dL}$ & HBc-Ab & $(-)$ \\
& & HCV-Ab & $(-)$ \\
& & &
\end{tabular}

\section{Karger' ${ }^{\prime \prime}$}




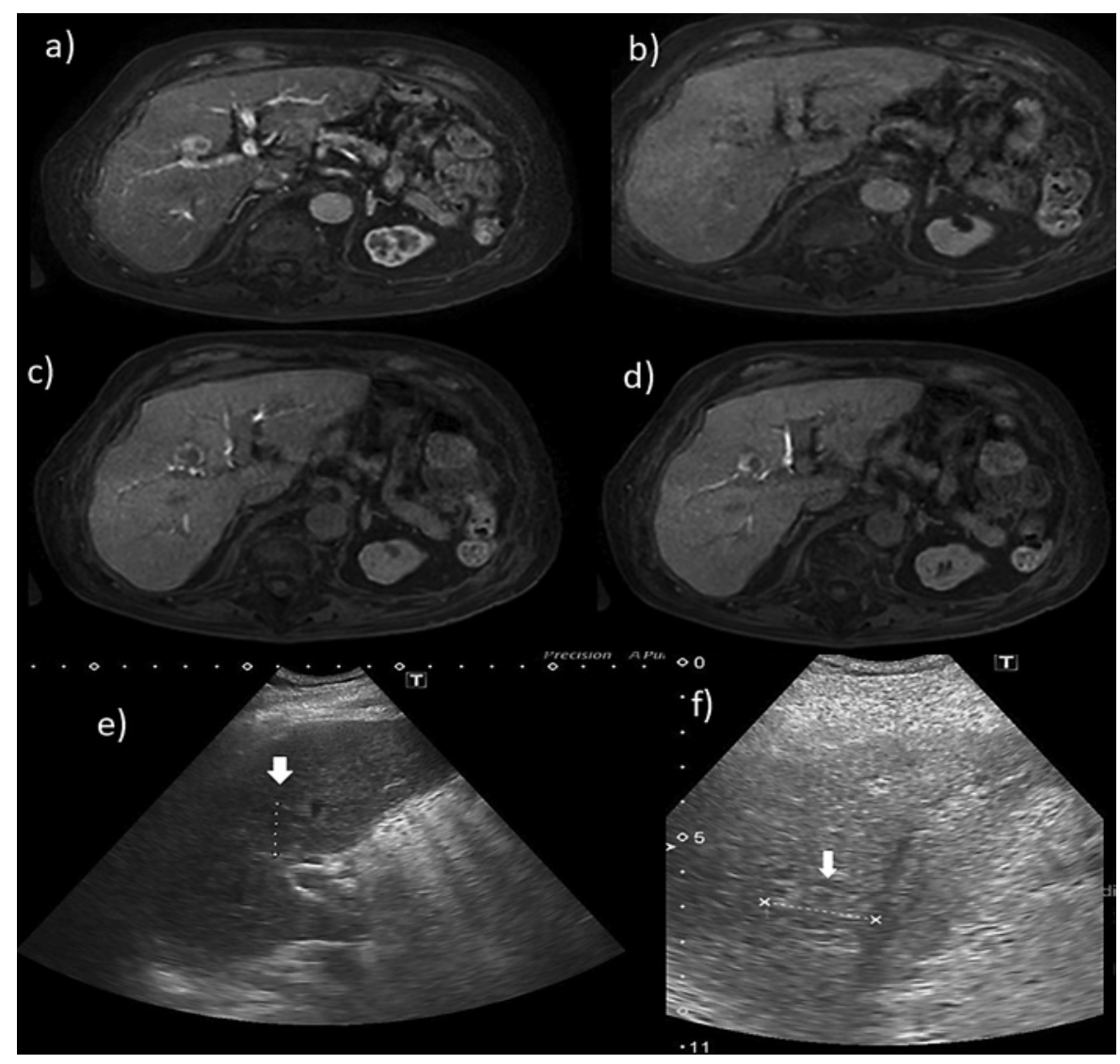

Fig. 1. EOB-MRI. a In the arterial phase, the tumor is enhanced and exists in S8. b In the portal phase, the tumor loses vascularity. $\mathbf{c}, \mathbf{d}$ In the hepatobiliary phase, the tumor clearly exists on the right-lobe front branch and adjacent to the B5 and B8 branches. e, $\mathbf{f}$ Ultrasound sonography indicates that the tumor is adjacent to the main bile branch.

from the patient regarding the treatment method. Therefore, we chose a method that can achieve sufficient ablation and avoid bile duct damage.

Gd-EOB-DTPA-enhanced MRI (EOB-MRI) revealed liver morphology consistent with chronic alcoholic liver injury. In the arterial phase, a hypervascular tumor of approximately $24 \mathrm{~mm}$ in diameter was visible. The hepatobiliary phase clearly demonstrates that the tumor was located near the main bile duct (Fig. 1a-d). Ultrasonography confirmed that the tumor was located near the hilar region (Fig. 1e, f, Fig. 2). A bile duct that could be punctured while avoiding the tumor was isolated and secured with a 21-G elastor needle in B8. Using a microguidewire, the outer needle was inserted into the right branch of the bile duct. The outer jacket of the needle was fixed and flash-cooled with saline. The tumor was ablated while refluxing cold saline into the bile duct. Computed tomography after RFA indicated that the tumor, despite being present near the main bile duct, was sufficiently ablated (Fig. 3).

Bile duct complications associated with RFA typically have delayed onset. Computed tomography examination 2 months after treatment showed no bile duct injury in this case.

\section{Karger' ${ }^{\prime \prime}$}




\section{Case Reports in Oncology}

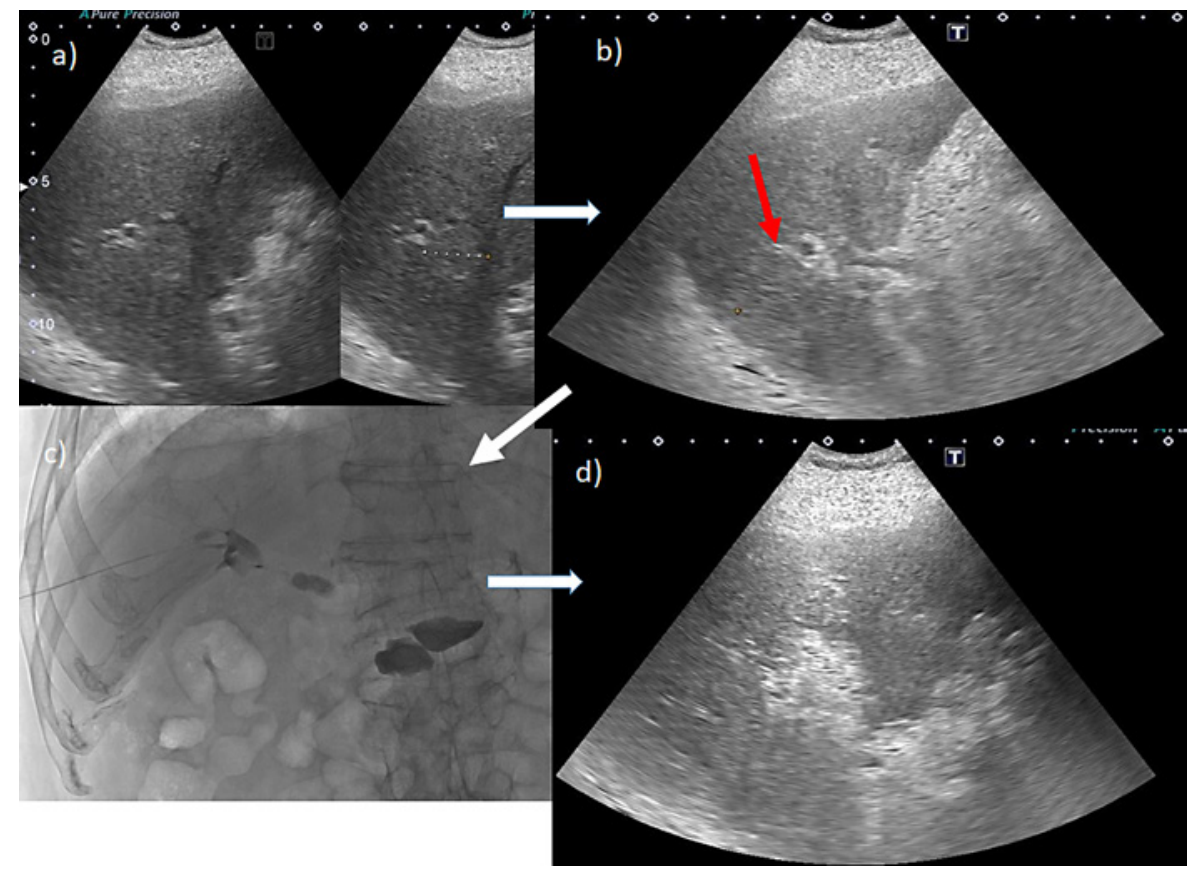

Fig. 2. a A bile duct B8 was identified as a candidate to secure the tumor without puncturing it. $\mathbf{b}$ The red arrow is the puncture line for securing B8. c After puncturing B8 and confirming that it is a bile duct by imaging, a plastic mantle of an elastor needle was advanced to the hilum using a microguidewire. $\mathbf{d}$ The tumor was ablated from the plastic mantle, while slowly recirculating semi-thawed saline.

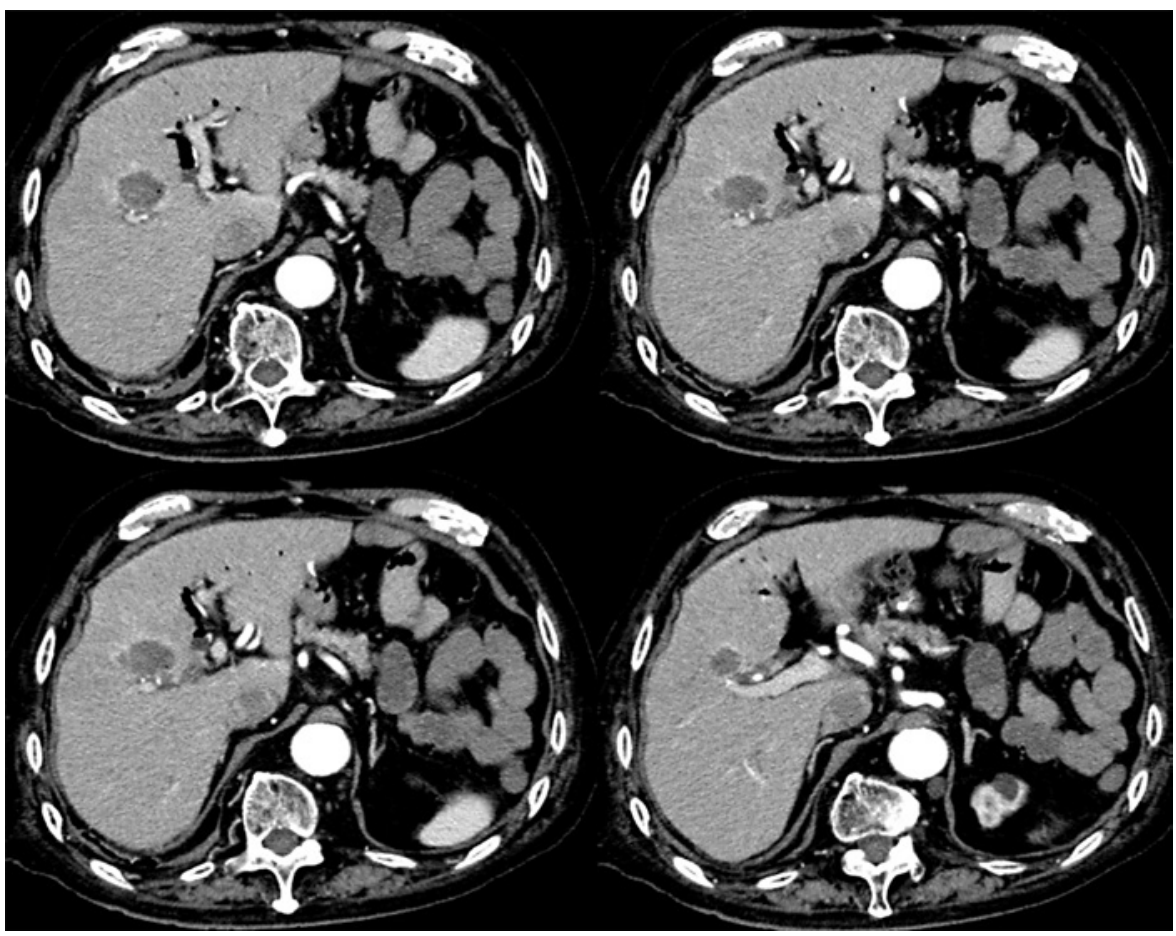

Fig. 3. After ablation of the tumor near the main bile duct, a sufficient safety margin was confirmed. 


\section{Case Reports in Oncology}

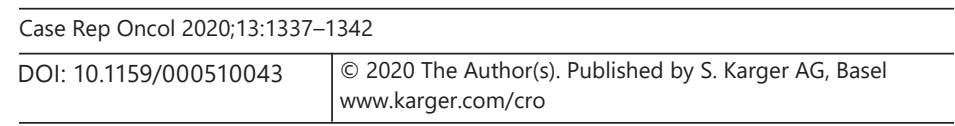

Takashima et al.: Avoiding Bile Duct Injury during RFA for HCC

\section{Discussion}

In Japan, more than $60 \%$ of HCC cases are diagnosed at an early stage (Barcelona Clinic Liver Cancer stage 0 or A), which can be treated with curative therapies, such as surgical resection, local ablation, and liver transplantation [2]. RFA is considered the standard treatment for HCC worldwide for patients with $<3$ tumors that are $<3 \mathrm{~cm}$ in diameter $[13,14]$. Maeda et al. [15] reported that among 11,298 RFA procedures, only 330 complications $(2.92 \%)$ were identified. Six patients $(0.064 \%)$ died from RFA-related complications during the recent period (2011-2015), and according to quality improvement guidelines for RFA of liver tumors, RFA is contraindicated for the treatment of tumors located $<1 \mathrm{~cm}$ from the main biliary duct or a bilioenteric anastomosis [9]. In Japan, the indications for RFA in patients with HCC tumors adjacent to the first or second branches of the bile duct have increased from 15 of 20 centers (75\%) during the previous period (1999-2010) to 21 of 25 centers (84\%) during the recent period. Indications have also increased for patients with a tumor near a bilioenteric anastomosis or papillary dysfunction from 5 of 20 centers (25\%) during the previous period to 10 of 25 centers (40\%) during the recent period, which has consequently increased performance of bile duct cooling via a nasobiliary drainage tube from 25 to $32 \%$ [15]. Ohnishi et al. [10] reported the utility of intraductal chilled saline perfusion (ICSP) to prevent bile duct injury during percutaneous RFA for HCC. Although there are similar subsequent reports, the complications of ENBD detention have been noted as a problem. The requirement for a longer hospital stay is an additional drawback. The method we present is simple and has very little impact on the medical economy. Although no large-scale studies have been done for this method, the therapeutic effect is considered to be equivalent to ENBD combination treatment.

Recently, Li et al. [12] reported that PTCD-ICSP appears to be a safe and effective technique for the management of larger HCC tumors $(>3 \mathrm{~cm})$ during microwave therapy. They reported that this method required 6- to 8.5-Fr tube insertion. Because of this, our method using the 21-G elastor needle has the potential to be safer and simpler, with shorter hospital stays and lower medical costs, which greatly benefits patients.

\section{Statement of Ethics}

This study was carried out in accordance with the Declaration of Helsinki. The patient had provided written informed consent to the cancer board of our institution before the procedure. Additionally, this patient provided written consent to publish this case (including publishing images).

\section{Conflict of Interest Statement}

The authors have no conflicts of interest to declare.

\section{Funding Sources}

The authors received no funding from any organization for this study. 


\section{Case Reports in Oncology}

Case Rep Oncol 2020;13:1337-1342

\begin{tabular}{l|l}
\hline DOI: $10.1159 / 000510043$ & (c) 2020 The Author(s). Published by S. Karger AG, Basel
\end{tabular} www.karger.com/cro

Takashima et al.: Avoiding Bile Duct Injury during RFA for HCC

\section{Author Contributions}

Hidetaka Takashima: formulation and execution of treatment methods; Michihisa Moriguchi, Natsuko Hayashi, Kyohei Ikeda, Kiyoshi Ogiso, Chihiro Yokomizo, Hirokazu Uejima, Tadashi Itoh, Hideo Tomioka, Shigeto Mizuno, Seiji Shimizu, Kohichiroh Yasui, and Yoshito Itoh: advice on treatment strategies.

\section{References}

1 Global Burden of Disease Liver Cancer Collaboration, Akinyemiju T, Abera S, Ahmed M, Alam N, Alemayohu MA, et al. The burden of primary liver cancer and underlying etiologies from 1990 to 2015 at the global, regional, and national level: results from the Global Burden of Disease Study 2015. JAMA Oncol. 2017 Dec; 3(12):1683-91.

2 Germani G, Pleguezuelo M, Gurusamy K, Meyer T, Isgrò G, Burroughs AK. Clinical outcomes of radiofrequency ablation, percutaneous alcohol and acetic acid injection for hepatocellular carcinoma: a meta-analysis. J Hepatol. 2010 Mar;52(3):380-8.

3 Kudo M, Izumi N, Kokudo N, Matsui O, Sakamoto M, Nakashima O, et al. Management of hepatocellular carcinoma in Japan: consensus-based clinical practice guidelines proposed by the Japan Society of Hepatology (JSH) 2010 updated version. Dig Dis. 2011;29(3):339-64.

4 European Association For The Study Of The Liver; European Organisation For Research And Treatment Of Cancer . EASL-EORTC clinical practice guidelines: management of hepatocellular carcinoma. J Hepatol. 2012 Apr;56(4):908-43.

5 Shiina S, Tateishi R, Arano T, Uchino K, Enooku K, Nakagawa H, et al. Radiofrequency ablation for hepatocellular carcinoma: 10-year outcome and prognostic factors. Am J Gastroenterol. 2012 Apr;107(4):569-78.

6 Wakamatsu T, Ogasawara S, Chiba T, Yokoyama M, Inoue M, Kanogawa N, et al. Impact of radiofrequency ablation-induced Glisson's capsule-associated complications in patients with hepatocellular carcinoma. PLoS One. 2017 Jan;12(1):e0170153.

7 Elias D, Sideris L, Pocard M, Dromain C, de Baere T. Intraductal cooling of the main bile ducts during radiofrequency ablation prevents biliary stenosis. J Am Coll Surg. 2004 May;198(5):717-21.

8 Livraghi T, Solbiati L, Meloni MF, Gazelle GS, Halpern EF, Goldberg SN. Treatment of focal liver tumors with percutaneous radio-frequency ablation: complications encountered in a multicenter study. Radiology. 2003 Feb;226(2):441-51.

9 Crocetti L, de Baere T, Lencioni R. Quality improvement guidelines for radiofrequency ablation of liver tumours. Cardiovasc Intervent Radiol. 2010 Feb;33(1):11-7.

10 Ohnishi T, Yasuda I, Nishigaki Y, Hayashi H, Otsuji K, Mukai T, et al. Intraductal chilled saline perfusion to prevent bile duct injury during percutaneous radiofrequency ablation for hepatocellular carcinoma. J Gastroenterol Hepatol. 2008 Aug;23(8 Pt 2):e410-5.

11 Ogawa T, Kawamoto H, Kobayashi Y, Nakamura S, Miyatake H, Harada R, et al. Prevention of biliary complication in radiofrequency ablation for hepatocellular carcinoma-cooling effect by endoscopic nasobiliary drainage tube. Eur J Radiol. 2010 Feb;73(2):385-90.

12 Li X, Yu J, Liang P, Yu X, Cheng Z, Han Z, et al. Ultrasound-guided percutaneous microwave ablation assisted by three-dimensional visualization operative treatment planning system and percutaneous transhepatic cholangial drainage with intraductal chilled saline perfusion for larger hepatic hilum hepatocellular $(D \geq 3 \mathrm{~cm})$ : preliminary results. Oncotarget. 2017 Jul;8(45):79742-9.

13 Kudo M, Matsui O, Izumi N, Iijima H, Kadoya M, Imai Y, et al. JSH consensus-based clinical practice guidelines for the management of hepatocellular carcinoma: 2014 update by the liver cancer study group of Japan. Liver Cancer. 2014 Oct;3(3-4):458-68.

14 Omata M, Cheng AL, Kokudo N, Kudo M, Lee JM, Jia J, et al. Asia-Pacific clinical practice guidelines on the management of hepatocellular carcinoma: a 2017 update. Hepatol Int. 2017 Jul;11(4):317-70.

15 Maeda M, Saeki I, Sakaida I, Aikata H, Araki Y, Ogawa C, et al. Complications after radiofrequency ablation for hepatocellular carcinoma: A multicenter study involving 9,411 Japanese patients. Liver Cancer. 2020 Jan; 9(1): 50-62. 